\title{
ВЛИЯНИЕ ЭЛЕКТРОЛИТА НА ЭФФЕКТИВНОСТЬ СВЯЗЫВАНИЯ ХОЛИНЭСТЕРАЗ С АФФИННЫМИ СОРБЕНТАМИ НА БАЗЕ ЗАМЕЩЕННЫХ ФЕНИЛЕНДИАМИНОВ
}

\author{
(Представил О. Эйзен)
}

Эффективность связывания специфических суб́стратов и ингибиторов с холинэстеразами (КФ 3.1.1.7, 3.1.1.8) зависит от концентрации электролита в реакционной среде $\left[{ }^{1-4}\right]$. Наблюдаемый при этом первичный солевой эффект можно объяснить ион-ионным взаимодействием катионных заместителей лигандов с т. н. анионным центром холинэстераз. Естественно предположить, что аналогичный солевой эффект проявляется также при взаимодействии этих же ферментов с аффинными сорбентами, для синтеза которых в качестве лиганда использованы специфические ингг:биторы с аммониевыми заместителями. В настоящей работе соблюдение таких закономерностей проверялось экспериментально для ацетилхолинэстеразы яда кобры и бутирилхолинэстеразы сыворотки крови лошади в случае 8 разных аффинных сорбентов, синтезированных на базе АН- и СН-агароз из мета-и парапроизводных фенилендиамина:

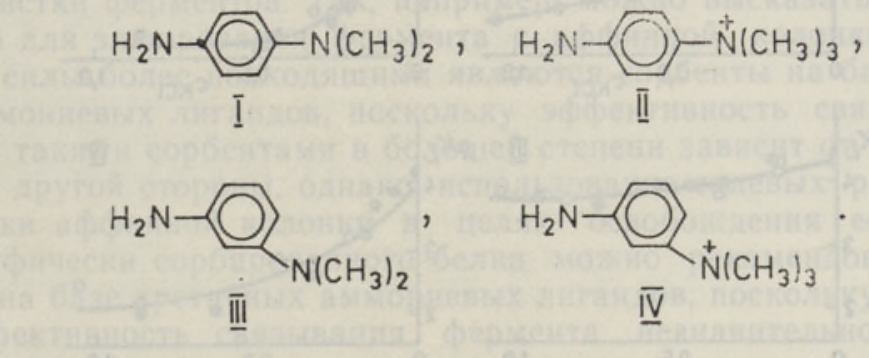

При этом эффективность связывания фермента с аффинными сорбентами определяли отдельно в маленьких пробах геля, что допускало расчет констант диссоциации $K_{L}$ комплекса фермента с сорбентом и непосредственное сопоставление полученных при этом данных о солевом эффекте с данными о влиянии соли на взаимодействие тех же ферментов с аналогичными обратимыми ингибиторами в растворе. Полученные результаты представляют не только теоретический, но и практический интерес, поскольку градиент ионной силы нередко используется для освобождения фермента с аффинного сорбента, что связано с изменением константы диссоциации комплекса фермент-сорбент в буферном растворе повышенной ионной силы.

Определенные в равновесных условиях константы диссоциации $K_{L}$ для комплекса фермента с аффинным сорбентом позволили охарактеризовать влияние электролита $(\mathrm{KCl})$ на равновесие комплексообразования в виде зависимости $p K_{L}$ от $c_{K C l}$. При этом важно отметить, что опыты проводились в $0,05 \mathrm{M}$ К-фосфатном буфере, что само по себе обеспечивало достаточно высокую ионную силу реакционной среды. Тем не менее добавленная в реакционную среду $\mathrm{KCl}$ в значительной степени 
влияла на величины $p K_{L}$. Полученные для обеих холинэстераз зависимости $p K_{L}$ от $c_{K с І}$ приведены на рис. 1 и 2 . На основе этих экспериментальных данных можно сделать следующие выводы.
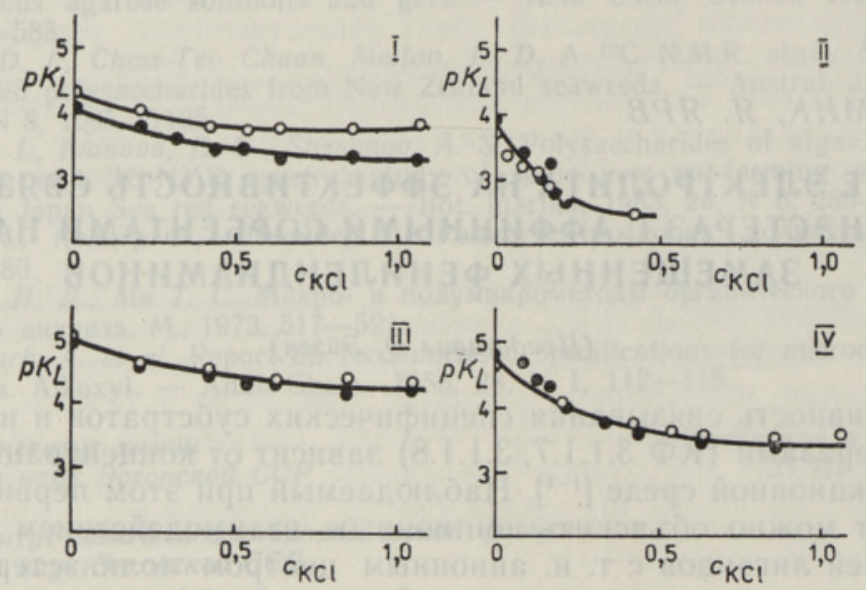

Рис. 1. Влияние концентрации электролита $(\mathrm{KCl})$ на константы диссоциации комплекса ацетилхолинэстеразы с аффинными сорбентами, синтезированными на базе $\mathrm{CH}$-агарозы (О) и АН-агарозы (-). Номера зависимостей соответствуют структурам лигандов I-IV (здесь и на рис. 2).
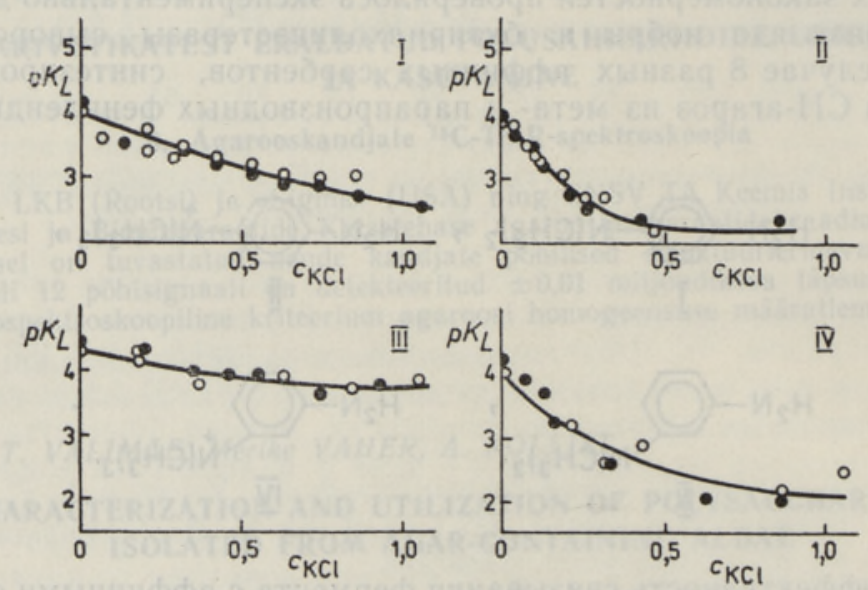

Рис. 2. Влияние концентрации электролита $(\mathrm{KCl})$ на константы диссоциации комплекса бутирилхолинэстеразы с аффинными сорбентами, синтезированными на базе $\mathrm{CH}$-агарозы (O) и АН-агарозы

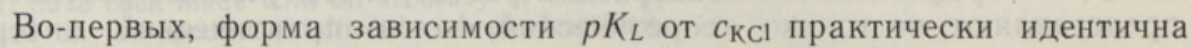
для сорбентов, синтезированных на базе АН- и СН-агароз.

Во-вторых, эффективность связывания ацетилхолинэстеразы и бутирилхолинэстеразы с теми же сорбентами характеризуется зависимостями одинаковой формы, хотя количественное сопоставление этих кривых затруднено из-за сложной ионной композиции реакционной среды, что не допускает определения ионной силы раствора.

B-третьих, форма зависимости $p K_{L}$ от $c_{K C l}$ для сорбентов с четвертичным и третичным атомами азота четко различается: в случае сорбента с четвертичным атомом азота наблюдается резкое падение эффектив-

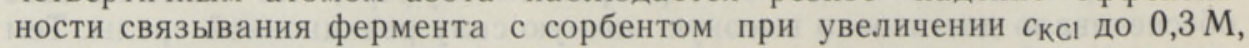
тогда как в присутствии более высоких концентраций соли в зависимости 
$p K_{\mathrm{L}}$ от $c_{\mathrm{KCl}}$ образуется «плато». Такая же форма зависимости $p K_{L}$ от

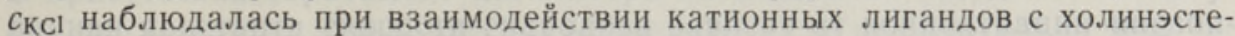
разами [5].

В настоящей работе в качестве модельного соединения для лиганда аффинного сорбента использовали 4-ациламино-N,N,N-триметилфениламмонийиодид, который является обратимым ингибитором холинэстераз.

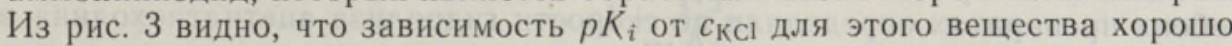
моделирует солевой эффект, обнаруженный в случае аффинных сорбентов. При этом изменение $p K_{i}$ при переходе от $0,05 \mathrm{M}$ фосфатного буфера к реакционной среде с добавкой концентрированного раствора $\mathrm{KCl}$ хорошо соответствует аналогичному изменению в величине $p K_{L}$. Иными словами, максимальная величина солевого эффекта одинакова для аммониевого лиганда в растворе и в составе сорбента.

Можно отметить, что качественно разный характер зависимости $p K_{L}$

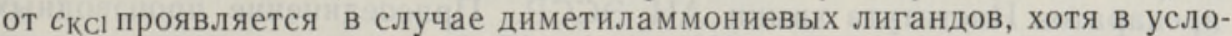
виях эксперимента (pH 7,50) эти ингибиторы тоже заряжены положительно. Как видно из рис. 1 и 2 , полученные для этих сорбентов зависимости имеют плоскую форму и в относительно широком интервале концентраций соли аппроксимируются в координатах $p K_{L}$ и $c_{K C l}$ прямой, соответствующей эффекту «высаливания». Важно отметить, что описанный в случае четвертичных аммониевых соединений первичный солевой эффект не обнаруживается в классической форме также при взаимодействии 4-N,N-диметиламинофенилацетанилида с ферментами в растворе. Из рис. 4 видно, что зависимость $p K_{i}$ от $c_{\text {Kсl }}$ существенно отличается от аналогичной зависимости для его четвертичного аналога.

Разный характер влияния соли на эффективность взаимодействия холинэстераз с аффинными сорбентами, синтезированными на базе четвертичных и третичных аммониевых лигандов, представляет определенный практический интерес с точки зрения методики хроматографической очистки ферментов. Так, например, можно высказать предположение, что для элюирования фермента с аффинной колонки градиентом ионной силы более подходящими являются сорбенты на базе четвертичных аммониевых лигандов, поскольку эффективность связывания фермента с такими сорбентами в большей степени зависит от концентрации соли. С другой стороны, однако, использование солевых растворов для промывки аффинной колонки в целях освобождения ее от остатков неспецифически сорбированного белка можно рекомендовать для сорбентов на базе третичных аммониевых лигандов, поскольку в таком случае эффективность связывания фермента незначительно меняется с ростом ионной силы раствора.

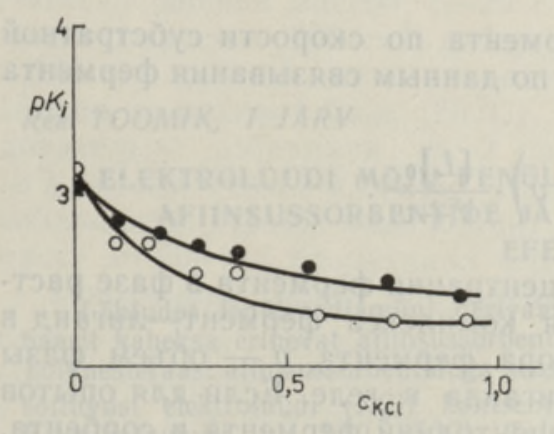

Рис. 3. Зависимость ннгибиторных свойств 4-ациламино-N,N,N-триметилфениламмонийнодида от концентрации электролита $(\mathrm{KCl})$ для ацетилхолинэстеразы (О) и бутирилхолинэстеразы

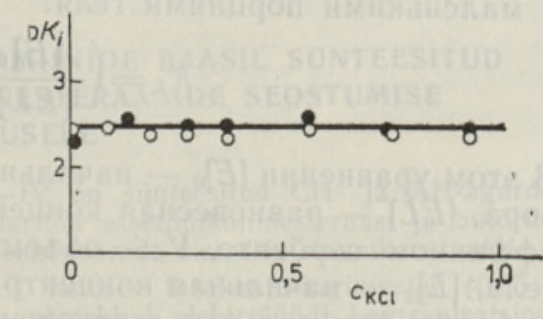

Рис. 4. Зависимость ингибиторных свойств 4-N,N-диметиламинофенилацетанилида от концентрации электролита $(\mathrm{KCl})$ для ацетилхолинэстеразы (О) и бутирилхолинэстеразы (О). 


\section{Экспериментальная часть}

В качестве источника ацетилхолинэстеразы использовали яд среднеазиатской кобры (Naja naja oxiana). Препарат VI класса бутирилхолинэстеразы сыворотки крови лошади был получен из Московского НИИ вакцин и сывороток им. И. И. Мечникова. Концентрацию фермента в обоих препаратах определяли по скорости гидролиза ацетилтиохолина в оптимальных условиях реакции [6].

Синтез аффинных лигандов 3-амино-N,N-диметиламинобензена (III), хлористого 3-амино-N,N,N-триметилфениламмония (IV), хлористого 4-амино-N,N,N-триметилфениламмония (II) описан в [ $\left.{ }^{7}\right] .4-\mathrm{Aмино-N,N-}$ диметиламинобензен (I) использовали в виде сульфата (Рсахим).

Аффинные сорбенты синтезировали исходя из гранулированной агарозы, выпускаемой Опытным заводом органического синтеза и биопрепаратов Института химии АН ЭССР. Присоединение производных фенилендиамина (I-IV) к CH-агарозе 4B (количество активных групп 15 мкмоль/мл) проводили с помощью 1-этил-3- (3-диметиламинопропил) карбодиимида при $\mathrm{pH} 4,5$ на основе методики [ $\left.{ }^{8}\right]$.

Для получения аффинного сорбента на базе АН-агарозы 4B (количество активных групп 18 мкмоль/мл) сначала проводили сукцинилирование носителя [9]. Присоединение производных фенилендиамина к этому носителю осуществляли карбодиимидным методом, как описано выше в случае СН-агарозы.

Для определения концентрации связанного с гелем лиганда использовали спектрофотометрический метод $\left[{ }^{10}\right]$. УФ-спектры сорбентов снимали на спектрофотометре «Perkin Elmer 420», используя суспензию геля в этиленгликоле (1:10 по объему).

Связывание холинэстераз с аффинными сорбентами в присутствии соли $(\mathrm{KCl})$ и без нее определяли по уменьшению активности фермента в пробах после добавления порций геля [7]. Активность холинэстераз определяли спектрофотометрическим методом [6], используя в качестве суб́страта ацетилтиохолиниодид (Реахим). Наличие соли не оказывало заметного влияния непосредственно на скорость ферментативного гидролиза ацетилтиохолиниодида, что связано с разбавлением реакционной смеси в 300 раз, а также с использованием 0,15 M K-фосфатного буфера при определении активности фермента.

Данные равновесного связывания ферментов с аффинными сорбентами анализировали исходя из равновесной схемы связывания

$$
E+L \stackrel{K_{L}}{\rightleftharpoons} E L
$$

определяя количество несвязанного фермента по скорости субстратной реакции. Расчет констант $K_{L}$ проводили по данным связывания фермента с маленькими порциями геля:

$$
K_{L}=\left(\frac{[E]_{0}}{[E L]} \cdot V-v\right) \cdot \frac{[L]_{0}}{V+v} .
$$

В этом уравнении $[E]_{0}$ - начальная концентрация фермента в фазе раствора, $[E L]$ - равновесная концентрация комплекса фермент-лиганд в аффинном сорбенте, $V$ - объем раствора фермента, $v$ - объем фазы геля, $[L]_{0}$ - начальная концентрация лиганда в геле. Если для опытов выбраны оптимальные соотношения концентраций фермента и сорбента, точность такой методики анализа составляет $15-20 \%$ [7].

Константы $K_{i}$ для обратимых ингибиторов определяли в бимолекулярных условиях субстратной реакции, где

$$
v=k_{\mathrm{II}}[S][E]=k_{\mathrm{I}}[S] .
$$


В присутствии обратимого ингибитора наблюдаемая псевдомономолекулярная константа скорости гидролиза зависит от концентрации ингибитора:

$$
k_{\mathrm{I}}^{\text {вабл }}=\frac{k_{\mathrm{I}}^{0}}{1+\frac{[I]}{K_{i}}} .
$$

Константы $K_{i}$ рассчитывали из зависимости $k_{\mathrm{I}}^{0} / k_{\mathrm{I}}^{\text {набл }}$ от $[I]$ методом линейных наименьших квадратов. Опыты проводили на спектрофотометpe «Perkin Elmer 420» $\left(0,05 \mathrm{M}\right.$ К-фосфатный буфер, $\left.\mathrm{pH} 7,50,25^{\circ} \mathrm{C}\right)$, используя в качестве субстрата ацетилтиохолиниодид для обоих типов холинэстераз.

\section{Л И ТЕ РА Т У РА}

1. Myers, D. K. Effect of salt on the hydrolysis of acetylcholine by cholinesterase. Arch. Biochem. and Biophys., 1952, 37, N 2, 469-487.

2. Бресткин А. П., Шатаева $Г$. А. Влияние хлоридов калия и кальция на антихолинэстеразную активность эфиров дифенилфосфиновой и дифенилтиофосфиновой кислот. - Изв. АН СССР. Сер. хим., 1975, № 6, 1337-1341.

3. Бресткин А. П., Шатаева Г. А. О влиянии хлоридов щелочных и щелочноземельных металлов на скорость ингибирования холинэстераз фосфорорганическими ингибиторами. - Изв. АН СССР. Сер. хим., 1975, № 7, 1538-1544.

4. Myers, D. K. Effect of electrolytes on cholinesterase inhibition. - Arch. Biochem., $1950,27, \mathrm{~N} 2,341-347$.

5. Нгумнова Н. Д., Аавиксаар А. А., Богатков С. В. Влияние неорганических солей на взаимодействие бутирилхолинэстеразы с $\mathrm{N}$-мегилкарбамоилхолином. - Биоорган. хим., 1978, 4, № 5, 961-971.

6. Ellmann, G. L., Courtney, K. D., Andres, V. Jr., Featherstone, R. M. A new and rapid colorimetric determination of acetylcholinesterase activity. - Biochem. Pharmacol., 1961, 7, 88-95.

7. Тоомик Р., Эллер М., Ярв Я. Взаимодействие холинэстераз с аффинными сорбентами на базе производных фенилендиамннов. - Изв. АН ЭССР. Хим., 1988, 37, № $1,30-36$.

8. Practical Guide for Use in Affinity Chromatography and Related Techniques. Réactifs IFB-Société Chimique Pointet-Girard, 1983, 134, 126.

9. Cuatrccasas, $P$. Protein purification by affinity chromatography. Derivatizations of agarose and polyacrylamide beads. - J. Biol. Chem., 1970, 245, N 12, 30593065 .

10. Туркова Я. Аффинная хроматография. М., 1980, 62-103.

Тартуский государственный университет
Поступила в редакцию

$1 /$ XII 1987

\section{ELEKTROLOUDI MOJU FENULEENDIAMIINIDE BAASIL SONTEESITUD AFIINSUSSORBENTIDE JA KOLIINESTERAASIDE SEOSTUMISE EFEKTIIVSUSELE}

Lähtudes fenüleendiamiini derivaatidest $\mathrm{I}-\mathrm{IV}$ on sünteesitud $\mathrm{CH}$ - ja $\mathrm{AH}$-agaroosi baasil kaheksa erinevat afiinsussorbenti ning uuritud atsetüülkoliinesteraasi ja butürüülkoliinesteraasi afiinsussorbentidega seostumise reaktsioonide dissotsiatsioonikonstantide $K_{L}$ sõltuvust elektrolüüdi $(\mathrm{KCl})$ kontsentratsioonist lahuses tasakaalutingimustel $(0,05 \mathrm{M}$ $\mathrm{K}$-fosfaatpuhver, $\left.\mathrm{pH} 7,50,25^{\circ} \mathrm{C}\right)$. Tulemusi on vōrreldud elektrolüüdi kontsentratsiooni mõjuga vastavate atsüülaniliidide inhibeerimiskonstantidele $K_{i}$, mis määrati atsetüültiokoliini hüdrolüüsireaktsioonil ning näidatud, et dissotsiatsioonikonstantide ja elektrolüüdi kontsentratsiooni vahelist sõltuvust ei mōjuta sorbendi loomus $(\mathrm{CH}$ - vồi $\mathrm{AH}$-agaroos) ega atsetüülkoliinesteraasi asendamine butürüülkoliinesteraasiga. $K_{L^{-i}}$ sõltuvus soola kontsentratsioonist niihästi lahuses kui ka afiinsussorbendi koostises on märgatavalt erinev tertsiaarsete ja kvaternaarsete ligandide puhul. 


\section{THE INFLUENCE OF ELECTROLYTE ON THE BINDING EFFECTIVENESS OF CHOLINESTERASES WITH AFFINITY SORBENTS ON THE BASIS OF PHENYLENDIAMINE DERIVATIVES}

Proceeding from $\mathrm{CH}$ - and $\mathrm{AH}$-agaroses 8 different affinity sorbents were synthesized, using phenylendiamine derivatives I-IV as affinity ligands. Binding of acetyl cholinesterase and butyrylcholinesterase with these sorbents has been studied under the equilibrium conditions $\left(0.05 \mathrm{M}\right.$ K-phosphate buffer, $\left.\mathrm{pH} 7.50,25^{\circ} \mathrm{C}\right)$ and the appropriate dissociation constants $K_{L}$ were determined as a function of salt $(\mathrm{KCl})$ concentration. These results were compared with the effects of salt concentration on the inhibitory constants $K_{i}$ for the model compounds, the acetylanilides of ligands I and II, determined from the inhibition by these compounds of the cholinesterase-catalyzed hydrolysis of acetylthiocholine. It has been shown that the interaction of the enzymes with affinity sorbents does not depend on the nature of the sorbent ( $\mathrm{CH}$ - or $\mathrm{AH}$-agarose). In the case of both cholinesterases the effectiveness of enzyme interaction with the ligands strongly depends on the presence of electrolyte for quaternized derivatives of phenylendiamine, while the dependence is weak in case of ligands with dimethylamino group. This conclusion is valid concerning the ligands both in solution and in the sorbent-bound state. 